\title{
Comparison of dexmedetomidine and clonidine as an adjuvant to levobupivacaine in supraclavicular brachial plexus block
}

\author{
Kataria A.P. ${ }^{1}$, Jarewal V. ${ }^{2}$, Singh G. ${ }^{3}$, Attri JP. ${ }^{4}$ \\ ${ }^{1}$ Dr Amar Parkash Kataria, Professor, ${ }^{2}$ Dr Vishal Jarewal, Senior Resident, ${ }^{3}$ Dr Gurpal Singh, Junior Resident, ${ }^{4}$ Dr \\ Joginder Pal Attri, Associate Professor, all authors are affiliated with Department of Anaesthesia, Government Medical \\ College, Amritsar (Punjab), India.
}

Address for Correspondence: Dr Joginder Pal Attri, Associate Professor, Department of Anaesthesia, Government Medical College, Amritsar (Punjab), India. E-mail: jpattri12@yahoo.co.in

\begin{abstract}
Introduction: There are always efforts to find better and safer local anaesthetics along with adjuvants for supraclavicular brachial plexus block. Levobupivacaine has strongly emerged as a safer alternative for regional anaesthesia than its racemic sibling bupivacaine. Alpha 2 agonists are combined with local anaesthetics to improve the quality of regional anaesthesia. Method: A prospective randomized study was carried out which included 60 adult patients between the ages of 18-65 years of ASA grade I and II who underwent upper limb orthopaedic surgeries. Group A received $30 \mathrm{ml}$ of $0.5 \%$ levobupivacaine with $150 \mu \mathrm{g}$ of clonidine and Group B received admixture of $30 \mathrm{ml}$ of $0.5 \%$ levobupivacaine with 100 $\mu \mathrm{g}$ of Dexmedetomidine. Onset, duration of sensory and motor blockade and duration of analgesia were observed. Results: Duration of postoperative analgesia in group A was $14.36 \pm 0.36$ minutes and in group B was $16.90 \pm 2.29$ minutes. Hence from the above observation, the duration of analgesia in group B is longer than group A which is statistically highly significant $(\mathrm{p}<0.001)$. Conclusion: Dexmedetomidine as an adjuvant $0.5 \%$ levobupivacaine is more effective in prolonging the duration of sensory and motor block and post operative analgesia compare to clonidine as an adjuvant to $0.5 \%$ levobupivacaine.
\end{abstract}

Keywords: Supraclavicular brachial plexus block, Levobupivacaine, Dexmedetomidine, Clonidine

\section{Introduction}

Pain is one of the most unpleasant feelings encountered by a patient undergoing surgical procedure. One of the greatest services an anaesthesiologist does to his patients is to acquire skill in alleviation of pain. Any deliberate interruption of signals travelling along a nerve is known as Regional Nerve Blockade. Regional blockade is anaesthesia of choice for emergency operations especially when the patients are full stomach $[1,2]$. Surgical procedures on the upper limb are ideally suited for regional anaesthesia as they are associated with higher degree of success and lesser degree of complications [3]. The advantages of the use of brachial plexus anaesthesia over general anaesthesia are apparent but it was still less used by anaesthesiologists due to few disadvantages like high failure rate, pleural

Manuscript received: 04 $4^{\text {th }}$ April 2017

Reviewed: $12^{\text {th }}$ April 2017

Author Corrected: 20 ${ }^{\text {th }}$ April 2017

Accepted for Publication: $30^{\text {th }}$ April 2017 injury causing pneumothorax and proximity to major vessels [1]. However, various newer techniques of depositing the drug perineurally and after identifying the nerves with nerve locator or with ultrasound have reduced these disadvantages to the minimum. Various investigators practiced supraclavicular approach and used a variety of local anaesthetic agents to perform an ideal and complete block.

Numerous studies have been conducted to find out a local anaesthetic which provides a good quality block with good safety profile. Commonly used local anaesthetics for peripheral nerve blocks include lignocaine, mepivacaine, bupivacaine and ropivacaine. Levobupivacaine is a new local anaesthetic which provides good quality block and a good safety profile [4]. Most studies have shown that levobupivacaine is comparable to bupivacaine and ropivacaine in clinical 
action i.e. duration of block and analgesia but has lesser toxicity profile [5].

The analgesia can further be enhanced and prolonged by the addition of various adjuvants to the local anaesthetic drugs. These drugs also reduce the dose of the local anaesthetic besides enhancing efficacy and reducing the incidence of adverse reaction [6]. Clonidine had been used as an adjunct to local anaesthetic agents in various regional techniques to extend the duration of block. Few studies showed that clonidine prolongs the effects of local anaesthetics but other studies have failed to show any effect of clonidine $[7,8]$.

Moreover, others have indicated an increased incidence of adverse effects such as sedation, hypotension and bradycardia [9]. Dexmedetomidine is a highly selective $\alpha 2$ adrenergic agonist with an affinity of eight times greater than clonidine [10]. Various studies have shown that dexmedetomidine prolonged the duration of sensory and motor block and provides very good analgesia when used as an adjuvant to local anaesthetics for nerve blocks $[11,12]$.

We observed that there were limited number of studies evaluating the effect of dexmedetomidine in brachial plexus block and how it is comparable with clonidine. Also there was no consensus on the dose of dexmedetomidine to be used for the brachial plexus block. As there was paucity of data in this regard, we planned a study in our institute to evaluate the effects of adding dexmedetomidine in levobupivacaine in comparison with clonidine in levobupivacaine in supraclavicular brachial plexus block in upper extremity orthopaedic surgeries in ASA grade I and II patients.

Aims and objectives of the study are to evaluate and compare levobupivacaine with dexmedetomidine and levobupivacaine with clonidine for:

- Onset and duration of sensory block

- Onset and duration of motor block

- Duration of analgesia

- Adverse reaction if any (Bradycardia, Hypotension, Oxygen saturation, sedation score) using the supraclavicular brachial plexus technique.

\section{Material and method}

A prospective, randomised, double blind, single-centre study was undertaken after the approval of our institution's ethical and scientific committee. Sixty patients of American Society of Anaesthesiologists (ASA) grade I and II of age group 18 - 65 years of either sex, admitted in the orthopaedic department of our institution and scheduled to undergo surgery of the forearm or hand were included. An informed and written consent was taken from all the participants.

Patients were divided into two groups of 30 each and groups were allocated randomly using sealed envelopes. Group A patients received $30 \mathrm{ml}$ of $0.5 \%$ levobupivacaine hydrochloride plus $1 \mathrm{ml}$ clonidine $(150 \mu \mathrm{g})$ while group B patients received $30 \mathrm{ml}$ of $0.5 \%$ levobupivacaine hydrochloride plus $1 \mathrm{ml}$ dexmedetomidine $(100 \mu \mathrm{g})$. A pre-anaesthetic check up was carried out a day before surgery. The interpretation of the visual linear analogue scale was explained one day prior to the surgery to the selected patients taken for the study to determine the analgesia in the post operative period. This was carried out with a $10 \mathrm{~cm}$ line. The $1^{\text {st }}$ end marked ' 0 ' means 'no pain' and last end marked '10' means 'severe pain'. The patients were asked to mark the severity of pain experienced at that time in the post operative period. All patients received tablet alprazolam $0.25 \mathrm{mg}$ orally one night prior to surgery. On the day of surgery, injection glycopyrrolate $0.2 \mathrm{mg}$ was given 45 minutes before surgery. Intravenous line was secured with $18 \mathrm{G}$ angiocath and the patients were preloaded with $10 \mathrm{ml}$ per $\mathrm{kg}$ body weight of ringer lactate solution over 15- 20 minutes. Base line respiratory rate, pulse rate, non invasive blood pressure, $\mathrm{SpO}_{2}$ and ECG were recorded. Oxygen was routinely administered via oxygen mask with $6 \mathrm{~L} / \mathrm{min}$. The patient was placed in a supine position with the head turned away from the side to be blocked. The ipsilateral arm of the patient was adducted and the hand was extended along the side towards the ipsilateral knee as far as possible.

The posterior border of the sternocleidomastoid was palpated and the palpating fingers then rolled over the anterior belly of the scalene muscle into the interscalene groove and a mark was made approximately 1.5 to 2.0 $\mathrm{cm}$ position to the midpoint of the clavicle. Palpation of subclavian artery at the site confirmed the landmark. After appropriate skin preparation and infiltration with local anaesthetic, $22 \mathrm{G} 100 \mathrm{~mm}$ insulated short bevelled needle was introduced at the specific land mark and a nerve stimulator was set at a current of $2 \mathrm{~mA}$ and a frequency of $2 \mathrm{~Hz}$. As the nerve was approached, movement of the wrist or fingers elicited and the current 
was gradually reduced to $0.4 \mathrm{~mA}$. The end point was taken when hand twitches could be elicited at a current of $0.4 \mathrm{~mA}$. The local anaesthetic was given in $5 \mathrm{ml}$ increments, aspiration before each bolus to avoid intravascular injection. Patient was monitored closely after completing the local anaesthetic injection. During the whole operative procedure, the analgesia was closely observed. Pulse, respiration and blood pressure were recorded initially every 5 minutes for 30 minutes thereafter at every 10 minutes for 60 minutes, after that every 15 minutes interval till the completion of procedure.

During the whole procedure, the extent and duration of anaesthesia and the amount of muscular relaxation was observed. Patients were assessed for loss of sensation to pin prick over the C5 - T1 dermatomes using a three point's scale every 2 minutes for the first 20 minutes and every 5 minutes thereafter till 30 minutes. A score of 2 for Sensory and 3 for Motor blockade was taken as successful block. Time of onset of sensory and motor blockade was recorded. Surgical incision was allowed to begin once full surgical anaesthesia i.e. complete block had been established. Pain score was assessed every 30 minutes during surgery. In case patient experienced mild pain (VAS $\leq 3$ ), injection ketamine $0.5 \mathrm{mg}$ per $\mathrm{kg}$ was given as intra operative supplementation and was repeated within 10 minutes interval to a maximum of two times, after which the patient was given general anaesthesia and excluded from study. Similarly block if considered to have failed when sensory anaesthesia was not achieved within 30 minutes, was excluded from the study. The patients were monitored for side effects and complications of technique and drugs throughout intra operative and post operative period. Any complications including side effects of the drugs used were noted and documented.

Analysis of data- The data was systematically collected, compiled and statistically analysed after the completion of the study and summarized as mean \pm standard deviation or as percentages. Numerical variables were normally distributed and were compared using Chi Square test for non-parametric data and Student ' $t$ ' test for parametric data using SPSS software. $P$ value of less than 0.05 was considered significant and less than 0.001 as highly significant.

\section{Results}

In present study both the groups were comparable with respect to age, sex ratio, weight, ASA grading, duration of surgery, baseline haemodynamic parameters and intra operative supplementation with ketamine as shown in table 1 .

Table-1

\begin{tabular}{|c|c|c|c|c|c|}
\hline \multicolumn{2}{|c|}{ Parameters } & Group A & Group B & $p$ value & Significance \\
\hline \multicolumn{2}{|l|}{ Age (Yrs) } & $34.33 \pm 13.16$ & $37.16 \pm 12.86$ & 0.265 & NS \\
\hline \multirow[t]{2}{*}{ Sex } & Male (\%) & 66.66 & 70 & \multirow[b]{2}{*}{0.781} & \multirow[b]{2}{*}{ NS } \\
\hline & Female $(\%)$ & 33.33 & 30 & & \\
\hline \multicolumn{2}{|c|}{ Weight Distribution } & $62.05 \pm 10.68$ & $61.90 \pm 12.35$ & 0.947 & NS \\
\hline \multirow[t]{2}{*}{ ASA grading } & Grade I & 73.33 & 76.66 & \multirow[b]{2}{*}{0.760} & \multirow[b]{2}{*}{ NS } \\
\hline & Grade II & 26.66 & 23.33 & & \\
\hline \multirow[t]{2}{*}{$\begin{array}{l}\text { Supplementation with } \\
\text { ketamine }\end{array}$} & $\begin{array}{c}\text { with } \\
\text { supplement } \\
\text { ation }\end{array}$ & 3 & 2 & \multirow[b]{2}{*}{0.554} & \multirow[t]{2}{*}{ NS } \\
\hline & $\begin{array}{c}\text { Without } \\
\text { supplement } \\
\text { ation }\end{array}$ & 27 & 28 & & \\
\hline \multicolumn{2}{|c|}{ RR (PER MIN) } & $15.05 \pm 1.07$ & $15.20 \pm 1.26$ & & \\
\hline \multicolumn{2}{|c|}{ PR (PER MIN) } & $81.37 \pm 6.75$ & $82.80 \pm 8.97$ & & \\
\hline \multicolumn{2}{|c|}{ SBP (MM Hg) } & $130.70 \pm 9.29$ & $34.60 \pm 10.16$ & & \\
\hline \multicolumn{2}{|c|}{ DSP (MM Hg) } & $77.36 \pm 5.73$ & $75.67 \pm 7.30$ & & \\
\hline \multicolumn{2}{|c|}{ SPO2 (\%) } & $99.87 \pm 0.13$ & $99.90 \pm 0.10$ & & \\
\hline
\end{tabular}

NS: Non significant 
Mean heart rate, respiratory rate, mean systolic and diastolic blood pressure, mean oxygen saturation in first 180 minutes were also comparable in both the groups. Incidence of any adverse effects or side effects was also observed to be

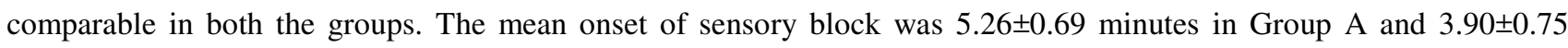
minutes in Group B and the mean onset of motor block was $9.00 \pm 1.33$ minutes in Group A and $7.93 \pm 0.73$ minutes in Group B. Hence early onset of sensory and motor block in group B was observed, with the difference in the two groups being statistically significant ( $p$ value $<0.05$ ). The mean duration of sensory block in Group A was $11.90 \pm 0.81$ hours and in Group B was $14.93 \pm 0.89$ hours whereas the mean duration of motor block in Group A was $14.131 \pm 0.806$ hours and in Group B was $17.831 \pm 0.775$ hours. Group B show longer duration of sensory and motor block and the difference in the two groups was found to be statistically highly significant ( $p$ value $<0.001$ ). The mean duration of post operative analgesia was shorter in Group A (16.27 \pm 0.81 hours) than in Group B (19.23 \pm 0.98 hours) with the difference in the two groups being statistically highly significant $(\mathrm{p}<0.001)$ as shown in Table 2 .

Table-2: Showing mean duration of surgery, motor block and post operative analgesia in two groups

\begin{tabular}{|c|c|c|}
\hline & Group A & Group B \\
\hline Mean duration of surgery in hours & $11.90 \pm 0.81$ & $14.93 \pm 0.89$ \\
\hline Mean duration of Motor Block in hours & $14.131 \pm 0.806$ & $17.831 \pm 0.775$ \\
\hline Mean duration of post operative analgesia in hours & $16.27 \pm 0.81$ & $19.23 \pm 0.98$ \\
\hline
\end{tabular}

The mean number of analgesic doses in 24 hours in Group A (1.93 \pm 0.58) was significantly more than in Group B (1.13 $\pm 0.34)$. The VAS score was significantly better in Group B as compared to Group A depicting a longer duration of analgesia in the Group B ( $\mathrm{p}<0.05)$ (Table 3). Regarding patient satisfaction score, patients in Group B were more satisfied than those in Group A as the difference in the two Groups was found to be significant $(\mathrm{p}<0.05)($ Table 4$)$

Table-3: Intraoperative and Postoperative Vas Scores

\begin{tabular}{|c|c|c|}
\hline Time (Hours) & Group A & Group B \\
\hline 0.5 & 0 & 0 \\
\hline 1 & 0 & 0 \\
\hline 2 & 0 & 0 \\
\hline 3 & 0 & 0 \\
\hline 4 & 0 & 0 \\
\hline 5 & 0 & 0 \\
\hline 6 & 0 & 0 \\
\hline 7 & 0 & 0 \\
\hline 8 & 0 & 0 \\
\hline 10 & 0 & 0 \\
\hline 12 & $1.52 \pm 0.33$ & $0.55 \pm 0.40$ \\
\hline 15 & $3.10 \pm 0.79$ & $2.48 \pm 1.78$ \\
\hline 18 & $2.83 \pm 0.59$ & $1.49 \pm 0.72$ \\
\hline 21 & $2.70 \pm 0.75$ & $2.10 \pm 1.06$ \\
\hline 24 & $2.95 \pm 0.98$ & \\
\hline
\end{tabular}

Table-4: Patient Satisfaction Score

\begin{tabular}{|c|c|c|c|c|c|c|}
\hline \multirow[t]{2}{*}{ Score } & \multicolumn{2}{|c|}{ Group A } & \multicolumn{2}{|c|}{ Group B } & p value & Significance \\
\hline & No. & \%age & No. & \%age & \multirow{4}{*}{$<0.05$} & \multirow{4}{*}{$\mathrm{S}$} \\
\hline 3 (Good) & 3 & 10.00 & 0 & 0 & & \\
\hline 4 (Very good) & 15 & 50.00 & 10 & 33.33 & & \\
\hline 5 (Excellent) & 12 & 40.00 & 20 & 66.66 & & \\
\hline
\end{tabular}




\section{Discussion}

Upper limb regional anaesthesia by brachial plexus block has become a significant anaesthesiologist armamentarium as it can be used to provide both anaesthesia for surgery and analgesia thereafter. Brachial plexus provide complete relaxation of muscles of upper extremity, thus making approximation of tendons and fracture reduction easier. It reduces postoperative spasm, pain and edema due to sympathetic blockade of blood vessels.

Age is one of the determinants of sensory and motor block with peripheral nerve block. Brachial plexus block is suitable to patients of all age groups as shown by Bonica et al in their study on brachial block comprising patients of age ranging from 2.6 to 90 years [13]. However in our study, we included patients of age group 18 to 65 years. Difficulty in obtaining cooperation for regional blocks has made regional anaesthesia an uncommon sole anaesthetic technique in children. The base line and preoperative vital parameters were comparable in the two groups (as $\mathrm{p}>0.05$ ). Monitoring of vital parameters was done for 180 minutes. The differences in the two groups were statistically insignificant at all measured intervals. All the monitored hemodynamic parameters remain stable throughout surgery.

Onset of sensory block was defined when the patients achieved a VAS score of one (dull pain /analgesia to pin prick).The difference in the mean onset of sensory block in group A and in group B was found to be statistically highly significant $(\mathrm{P}<0.01)$. Sebastian et al found that dexmedetomidine when added to ropivacaine in supraclavicular brachial plexus block has faster onset of sensory and motor block [14]. Rao et al also concluded that the difference in the onset time of sensory and motor block were statistically significant when dexmedetomidine was added to bupivacaine in place of clonidine in supraclavicular brachial block [15]. Similarly Karthik et al (2015) concluded that dexmedetomidine as an adjuvant to levobupivacaine is statistically highly significant in onset of sensory and motor block than clonidine as adjuvant $(p<0.001)$ [16]. The surgeries were started when full surgical anaesthesia had developed. In case, patient experienced mild pain (VAS <3), intra operative supplementation was given with injection ketamine $0.5 \mathrm{mg}$ per $\mathrm{kg}$. The VAS score was 0 for all patients (except those who required ketamine supplementation) till about 6 hour in group A and 7 hour in group B, following which VAS score gradually increased and patients were given rescue analgesia in form of injection diclofenac sodium intramuscularly, when the VAS score $>3$. VAS score was checked for 24 hours after the block and rescue analgesia was given whenever it was more than three. The numbers of analgesic doses given within 24 hours were comparable. The duration of sensory block was taken when the patient again started feeling dull pain (VAS score of 1). The difference in the two groups was found to be statistically highly significant with group B having longer duration of sensory block. Similarly the difference in the two groups was statistically highly significant with group B having longer duration of motor block. This is in accordance with study done by Rao et al (2014). Hosali et al (2015) also concluded that addition of dexmedetomidine to levobupivacaine significantly prolonged the duration of sensory and motor block as compared to clonidine [17]. Karthik et al also (2015) also found that sensory and motor blockade were prolonged by addition of dexmedetomidine to levobupivacaine as compared to clonidine with levobupivacaine [16]. The duration was measured from the time of giving the block till first rescue analgesic was required. The difference in the groups was statistically highly significant $(\mathrm{p}<0.0001)$ with group B having a much longer duration of analgesia. This was in accordance with the study done by Hosalli et al [16]. Similar results were obtained by studies conducted by Karthik et al and Sebestian et al [14,16].

\section{Conclusion}

Dexmedetomidine is a better adjuvant than clonidine when added to levobupivacaine in supraclavicular brachial plexus block for orthopaedic surgeries as it is faster in onset and it prolongs the duration of sensory and motor blockade as well as the duration of analgesia.

\section{Funding: Nil, Conflict of interest: None} Permission of IRB: Yes

\section{References}

1. Nielsen KC, Steele SM. Ambulatory evaluation and safety considerations. Tech Reg Anesth Pain Management. 2004;8(2):99-103. DOI: http://dx.doi.org/10.1053/j.trap.2003.12.001 
2. Klein SM, Evans H, Nielsen KC, Tucker MS, Warner DS, Steele SM. Peripheral nerve block techniques for ambulatory surgery. Anesth Analg. 2005;101(6):166376. DOI:10.1213/01.ANE.0000184187.02887.24

3. Ward ME. The interscalene approach to brachial plexus. Anaesthesia 1974;29:147-57. DOI: 10.1111/j.1365-2044.1974.tb00613.x

4. Telivuo L. A new long acting local anaesthetic solution for pain relief after thoracotomy. Ann Chir Gynae Fenn. 1963;52:513-8. PMID:14083852

5. Tucker GT. Pharmacokinetics of local anaesthetics. Br J Anaesth. 1986; 58:717-31.

6. Esmaoglu A, Yegenoglu F, Akin A, Turk CY. Dexmedetomidine added to levobupivacaine prolongs axillary brachial plexus block. Anesth Analg. 2010;111:1548-51. doi: 10.1213/ANE.0b013e3181fa3095. Epub 2010 Oct 1.

7. Winne AP. Interscalene brachial plexus block. Anesth Analg. 1970;49(3):455-66.

8. Swami SS, Keniya VM, Ladi SD, Rao R. Comparison of dexmedetomidine and clonidine ( $\alpha 2$ agonist drugs) as an adjuvant to local anaesthesia in supraclavicular brachial plexus block: A randomised double-blind prospective study. Indian J Anaesth. 2012;56(3):243-9. DOI: 10.4103/0019-5049.98767

9. Casati A, Magistris L, Beccaria P, Cappelleri G, Aldegheri G, Fanelli G. Improving postoperative analgesia after axillary brachial plexus anesthesia with $0.75 \%$ ropivacaine. A double blind evaluation of adding clonidine. Minerva Anesthesiol 2001 May;67(5):40712.

10. Culebras X, Van Gessel E, Hoffmeyer P, Gamulin Z. Clonidine combined with a long acting local anesthetic does not prolong postoperative analgesia after brachial plexus block but does induce hemodynamic changes. Anesth Analg 2001 Jan;92(1):199-204.

11. Gertler R, Brown HC, Mitchell DH. Dexmedetomidine: a novel sedative- analgesic agent. Proc (Bayl Univ Med Cent) 2001 Jan;14(1):13-21

12. Raimo V, Juha M, Veijo S, Leena N, Virtanen R. Characterisation of selectivity, specificity and potency of dexmedetomidine as $\alpha 2$ adrenoceptor agonist. Eur J Pharmacol 1988;150:9-14.

13. Bonica JJ, Moore DC. Brachial plexus block. Am J Surg 1949;78:65-79.

14. Sebastian D, Ravi M, Dinesh K, Somasekharam P. Comparision of Dexmedetomidine and clonidine as Adjuvant to Ropivacaine in Supraclavicular Brachial Plexus Nerve Blocks. J of Dental and Medical Sciences 2015;14(3):91-7. DOI: 10.9790/0853-14359197

15. Rao KG, Kapoor P, Chaurasiya MK, Shukla A. A randomized double blind prospective study to compare coinidine and dexmedetomidine as an adjuvant in supraclavicular brachial block. Indian Journal of Fundamental and Applied Life Sciences. 2014;4:226-9.

16. Karthik G, Sudheer R, Sahajandanda H, Rangalakshimi S, Roshan K. Dexmedetomidine and clonidine as adjuvants to levobupivacaine in supraclavicular brachial plexus block: a comparative randomized prospective controlled study. JEMDS 2015;4(19):3207-21.

17. Hosalli V, Ganeshnavar A, Hulakund SY, Prakashappa DS. Comparison of dexmedetomidine and clonidine as an adjuvant to levobupivacaine in ultrasound guided axillary brachial plexus block: a randomized double blind prospective study. Int $\mathbf{J}$ Clinical and Diagnostic Research 2015; 3(2):1.

\section{How to cite this article?}

Kataria A.P., Jarewal V., Singh G., Attri JP. Comparison of dexmedetomidine and clonidine as an adjuvant to levobupivacaine in supraclavicular brachial plexus block. Int J Med Res Rev 2017;5(04):399-404. doi:10.17511/ijmrr. 2017.i04.05. 